\title{
WestVirginiaUniversity
}

THE RESEARCH REPOSITORY @ WVU

Faculty \& Staff Scholarship

Spring 5-4-2020

\section{The Relationship Between Campus Recreation Facility Use and Retention for First-Time Undergraduate Students}

\author{
Sera Janson Zegre \\ West Virginia University, Sera.Zegre@mail.wvu.edu \\ Rodney P. Hughes \\ West Virginia University, rodney.hughes@mail.wvu.edu \\ Andrew M. Darling \\ West Virginia University, andrew.darling@mail.wvu.edu \\ Craig R. Decker \\ University of Alabama, Birmingham, craigd@uab.edu
}

Follow this and additional works at: https://researchrepository.wvu.edu/faculty_publications

Part of the Higher Education Commons, and the Sports Studies Commons

\section{Digital Commons Citation}

Zegre, Sera Janson; Hughes, Rodney P.; Darling, Andrew M.; and Decker, Craig R., "The Relationship Between Campus Recreation Facility Use and Retention for First-Time Undergraduate Students" (2020). Faculty \& Staff Scholarship. 2086.

https://researchrepository.wvu.edu/faculty_publications/2086

This Article is brought to you for free and open access by The Research Repository @ WVU. It has been accepted for inclusion in Faculty \& Staff Scholarship by an authorized administrator of The Research Repository @ WVU. For more information, please contact beau.smith@mail.wvu.edu. 
The relationship between campus recreation facility use and retention for first-time undergraduate students

Sera Janson Zegre (iD $* 1$ Rodney Philip Hughes (iD ${ }^{2}$ Andrew Mark Darling ${ }^{1}$ Craig Robert Decker ${ }^{3}$ West Virginia University

\section{Author Notes}

The data that support the findings of the study are not publicly available because they contain potentially individually identifiable information that could compromise confidentiality. Authors can share variables used and a list of sample restrictions upon request, and data may be requested from the study institution with approval from the Institutional Review Board.

Correspondence concerning this article should be addressed to Sera.Zegre@mail.wvu.edu ${ }^{1}$

${ }^{1}$ Department of Campus Recreation PO Box 6018, Morgantown, WV 26506

${ }^{2}$ Higher Education Administration, Morgantown, WV 26506

${ }^{3}$ The University of Alabama at Birmingham, Department of University Recreation, 1501 University Blvd., Birmingham, AL 35294

\section{Acknowledgements}

The authors would like to acknowledge assistance and support from West Virginia University's Office of Institutional Research, specifically Liz Reynolds, Lawrence DeLeurere, and Megan Curran. Appreciation for support from Eric O’Hara, Associate Director West Virginia University Housing Services; G. Corey Farris, Dean of Students West Virginia University; Louis Slimak, Assistant Provost for Curriculum and Assessment at West Virginia University; and to Andrew 
Bourget and Rhonda Powers Northern Arizona University Campus Recreation. Data management and analysis adhere to IRB protocol \# 1805106824. 


\begin{abstract}
This study examines the relationship between campus recreation facility access and firstyear retention of full-time, first-time undergraduate students at a public university for 2014-15 through 2016-17. Authors examine differences between facility users and non-users by pairing facility swipe card data with student records. Statistical analysis includes logistic regression and matching approaches, controlling for student demographics, academic preparedness, academic goals, family characteristics, and various environmental factors. Results show a positive and significant relationship between recreation facility use and retention, including $7.1-8.4$ percentage points higher retention for users versus non-users, holding other variables constant. Subsample analysis suggests the relationship between recreation facility use and retention differs across student subgroups. Key study contributions include linking card swipe data on facility usage with extensive student records, clearly defining facility users and non-users, and introducing a new robustness check based on assignment of students to residence halls different distances from recreation facilities.
\end{abstract}

Keywords: institutional research, postsecondary retention, campus recreation, first-time undergraduate students 
The relationship between campus recreation facility use and first-year retention for

first-time undergraduate students

The fall-to-fall retention rate for first-year students at colleges and universities in the United States increased only 3.6 percentage points between 2009 and 2017, from 69.9 to 73.5 , according to recent evidence from the National Student Clearinghouse (NSC Research Center, 2019). Some student characteristics are predictive of differences in first-year retention rates, with Black, American Indian or Alaska Native, and first-generation students exhibiting lower retention rates than other students (NSC Research Center, 2019; Radunzel, 2018). At the same time, colleges and universities have begun to feel pressure from declining enrollments, given projections of national reductions in the number of high school graduates between 2014 and 2032, and with incoming classes smaller in 2032 than in 2013 (Bransberger \& Michelau, 2016; Grawe, 2018). In the face of stiffer competition recruiting a smaller number of prospective students that may yield lower tuition revenue, retention of students has become even more important for colleges and universities (Seidman, 2012; Tinto, 2006).

Past studies suggest both academic and social engagement are key determinants of student retention (Tinto, 1975, 1993, 2006; Soria \& Stebleton, 2012; Swail, 2004). Academic and social engagement encompass interactions with faculty, staff, and peers, time spent on academic tasks, and supports available to students from the campus environment and may include participation in specific practices like research, service-learning, and attendance at campus events (National Survey of Student Engagement, 2019). While campus resources outside the classroom may be underfunded on some campuses or seen as ancillary to students' experiences (Danbert, et al., 2014), many students spend time engaging with these resources. For example, a national benchmark survey found that 75 percent of students use on-campus 
recreation center facilities, programs, and services at their colleges or universities (Forrester, 2014). A growing body of literature in campus recreation includes evidence linking use of recreation facilities and participation in club and intramural athletics with higher retention, higher grade point average (GPA), and higher likelihood of degree completion (Danbert et al., 2014; Mayers, et al., 2017; McElveen \& Ibele, 2019; Roddy, et al., 2017; Vasold, Deere, \& Pivarnik, 2019; Vasold, Kosowski, \& Pivarnik, 2019).

Although the body of literature on the benefits of campus recreation for student success is growing, studies lack consistency and are primarily shared within the campus recreation field. As examples, studies may employ inconsistent definitions of recreation participants or facility users, and studies may not have access to a range of data or employ appropriate methods to minimize the salience of plausible alternative explanations for student outcomes. The authors of the present study seek to extend the existing and growing literature connecting recreation participation with student outcomes by taking a systematic approach to defining users; linking sources of data on students' recreation participation, retention, prior academic achievement, financial aid, program participation, race, and sex; and considering the potential for selection bias in recreation participation, while also connecting study findings around retention to implications for professionals and campus leaders across colleges and universities.

\section{Objectives}

Considering the importance of student retention against a backdrop of potentially declining numbers of prospective incoming students (Bransberger \& Michelau, 2016; Grawe, 2018), and to contribute to the literature connecting retention with campus recreation, we pursue two main research questions: 
(1) What is the relationship between campus recreation facility use and first-year retention, conditional on student demographic characteristics and prior academic achievement?

(2) How are findings robust to specification checks, including one in which students do not have full control over distances from their residence to the recreation facility?

Key methodological contributions of the study include the following: (a) linking card swipe data on facility usage with extensive student records on retention, prior academic achievement, financial aid, program participation, race, and sex; (b) clearly defining facility users and non-users; and (c) introducing complementary matching approaches, including one that compares outcomes for students assigned to residence halls that are different distances from recreation facilities. Remaining sections review existing literature, establish a theoretical framework, describe data and methods, present results, and consider implications for administrators working to improve institutional retention.

\section{Literature Review}

One of the most valued outcomes for colleges and universities nationwide is institutional retention or student persistence (Astin, 1984; Chen, 2012; McFarland, et al., 2019; Ryan, 2004; Shapiro et al., 2014; Tinto, 1975). Tinto (1975) explained that students must be integrated into both the academic and social communities of the institution to persist there. Given up to one third of college students drop out at the end of their first year (Ryan, 2004; Shapiro et al., 2014), first-time students are often the focus of institutional retention efforts. Literature suggests investments in programs that support students' social and academic engagement and integration (e.g. cultural events, intramural athletics, newspapers, organizations, and supplemental instruction) increase student academic success and retention (Astin, 1984; Chen, 2012; Long, 2008); this engagement is key during the crucial first year of college (Tinto, 2006). 


\section{Value of Engagement}

Astin's Theory of Involvement (1975) and Tinto's Theory of Departure (1975) both postulate that students who are engaged remain at their institutions. Astin (1993) proposed a positive relationship between academic outcomes and student involvement — and that student success includes engagement. This engagement is both social and academic in nature; Tinto (1975) suggested that students' persistence depends on their integration into their institutions' academic and social communities. Tinto (1993) also emphasized importance of the institutional environment beyond academics, highlighting the value of social systems given the positive relationship between students' peer involvement and student learning and persistence.

Retention literature specifically highlights the importance of student social engagement: specifically, the positive impact of meaningful peer interactions (Mayhew, et al., 2016). Studies evaluating the relationship between outdoor orientation programs and student persistence have affirmed the mediating role of psychological variables such as social support (Bell, 2006) and social connections (Gass, et al., 2003) in student persistence. Astin's (1984) theory of involvement specifically posed that extracurricular participation contributes to student success. Some research has found that participation in co-curricular activities (i.e., activities that complement learning experiences in the curriculum) support academic success and retention (Light 1992; Kuh, et al., 2008; Pascarella \& Terenzini, 2005). Studies on the impacts of outdoor orientation programs have reported significant relationships with student persistence, as well as with: academic success, college recruitment, employment opportunities, environmental connection, leadership skills, life effectiveness, physical fitness, and social connection (Andre, et al., 2017; Bell \& Chang, 2017; Gass, 1987, 1990; Michael, et al., 2017). Strayhorn (2008) 
reinforced a strong relationship between peer interactions and student learning outcomes, suggesting the value of collaborative activities like intramural sports.

\section{Value of Campus Recreation}

Campus recreation studies have shown a significant positive relationship between student participation and academic success like GPA, retention, and graduation (Belch, et al., 2001; Danbert et al., 2014; Leppel, 2005; McElveen \& Ibele, 2019; Roddy et al., 2017; Huesman, et al., 2007, 2009; Vasold, Deere, \& Pivarnik 2019; Vasold, Kosowski, \& Pivarnik, 2019), as well as personal health and wellness benefits (Brock, et al., 2015; Forrester, 2014; Zizzi, et al., 2004). Studies have shown benefits of campus recreation participation beyond academic outcomes, with recreation participation promoting skills like cooperation, communication, time management, multi-tasking and problem-solving, as well as sense of belonging, developing friendships, meeting new people, multi-cultural awareness, respect for others, stress relief, physical fitness, weight loss, and enjoyment (Forrester, 2014).

Previous studies have used various methods to quantify the value of campus recreation. Some used surveys of undergraduate students that examined student involvement and personal and academic benefits from participation (Brock et al., 2015; Forrester, 2014, 2015; Henchy, 2011; Leppel, 2005; Mayers et al., 2017; Miller, 2011; Vasold, Deere, \& Pivarnik 2019; Zizzi et al., 2004). While these surveys captured variables such as self-reported outcomes and behavioral intentions, card swipe data from recreational facilities measure actual behavior (i.e., at least an entry into the facility). Card swipe and official institutional data can be paired to include academic outcomes from a census of enrolled students versus a sample of survey respondents. Using this method, some studies have examined users only (Roddy et al., 2017), while others have examined differences in users and non-users using descriptive statistics and significance 
testing (Belch et al., 2001; Danbert et al., 2014; McElveen \& Ibele, 2019). Most research uses the number of recreation facility visits as a foundation to define users. In swipe card data analysis, most studies classified users as those who used the facility at least once (Belch et al., 2001; Kampf, \& Teske, 2013; Roddy et al., 2017). Finally, some studies have also assessed club and intramural sports participation (Astin, 1993; Kampf \& Teske, 2013; Light, 1992; McElveen \& Ibele, 2019; Vasold, Deere, \& Pivarnik 2019; Vasold, Kosowski, \& Pivarnik, 2019), also finding significantly higher academic outcomes in campus recreation employees than other students (Kampf \& Teske, 2013).

Some studies have assessed the value of campus recreation using regression (Kampf \& Teske, 2013; Roddy et al., 2017), but few have used extensive covariates to attempt to account for other determinants of student persistence (Huesman, et al., 2007, 2009; Kampf \& Teske, 2013; Vasold, Deere, \& Pivarnik 2019; Vasold, Kosowski, \& Pivarnik, 2019). Fewer studies have incorporated demographic or financial variables into the analysis (Huesman et al., 2007,2009; Vasold, Deere, \& Pivarnik 2019; Vasold, Kosowski, \& Pivarnik, 2019), as has been done with outdoor orientation programs (Bell \& Chang, 2017; Gass, 1987, 1990; Michael et al., 2017), nor included a variable for academic goals like Leppel (2001). Most studies assessed a single student cohort at one institution (Danbert et al., 2014; Huesman et al., 2007, 2009; Kampf, \& Teske, 2013; Roddy et al., 2017), whereas Belch et al. (2001) assessed three cohorts. Most recently, Vasold, Kosowski, and Pivarnik (2019) used a matching approach to estimate the relationship between intramural sports participation and retention, matching participants and non-participants on observable characteristics including sex, race, Pell Grant eligibility, firstgeneration student status, and high school GPA. However, regression and matching approaches assuming student groups are comparable on observable characteristics may leave out unobserved 
characteristics like awareness of campus resources, motivation, time management, and time working, which may be positively correlated with both retention and recreation participation; this may cause estimates of the relationship between retention and participation to be biased upward.

The present study incorporates observable variables including sex, race, Pell Grant receipt, first-generation status, and high school GPA, as well as other predictors of retention like initial academic major declaration and unmet financial need. Authors also create a new means of classifying participation to clearly define facility users and non-users. In an attempt to address the potential for unobserved characteristics to influence both students' participation in recreation and their retention outcomes, authors also match a sample of students who may be assigned to live close to a recreation facility for reasons unrelated to their unobserved characteristics with comparable students who live farther away. The assignment process for this sample of students ideally creates an opportunity to study retention outcomes when unobserved characteristics (like awareness of resources or motivation) play less of a role in students' decisions to use the facility.

\section{Theoretical Framework}

The authors of the present study offer a means of organization of variables important to student persistence as indicated in Figure 1. Astin (1984) provided a foundational college impact model, which includes inputs, environment, and outcomes, known as the IEO model of change. Figure 1 populates Astin's (1984) IEO model with concepts found to be significant to students' persistence in Mayhew et al.'s (2016) critical review related to college influence on students. The model includes variables that the authors seek to examine in this study. Concepts and variables are not meant to be exhaustive of all influences on student persistence, like more comprehensive comparisons (Seidman, 2012), but to demonstrate a means of variable organization. 
Figure 1: Conceptual model of student persistence

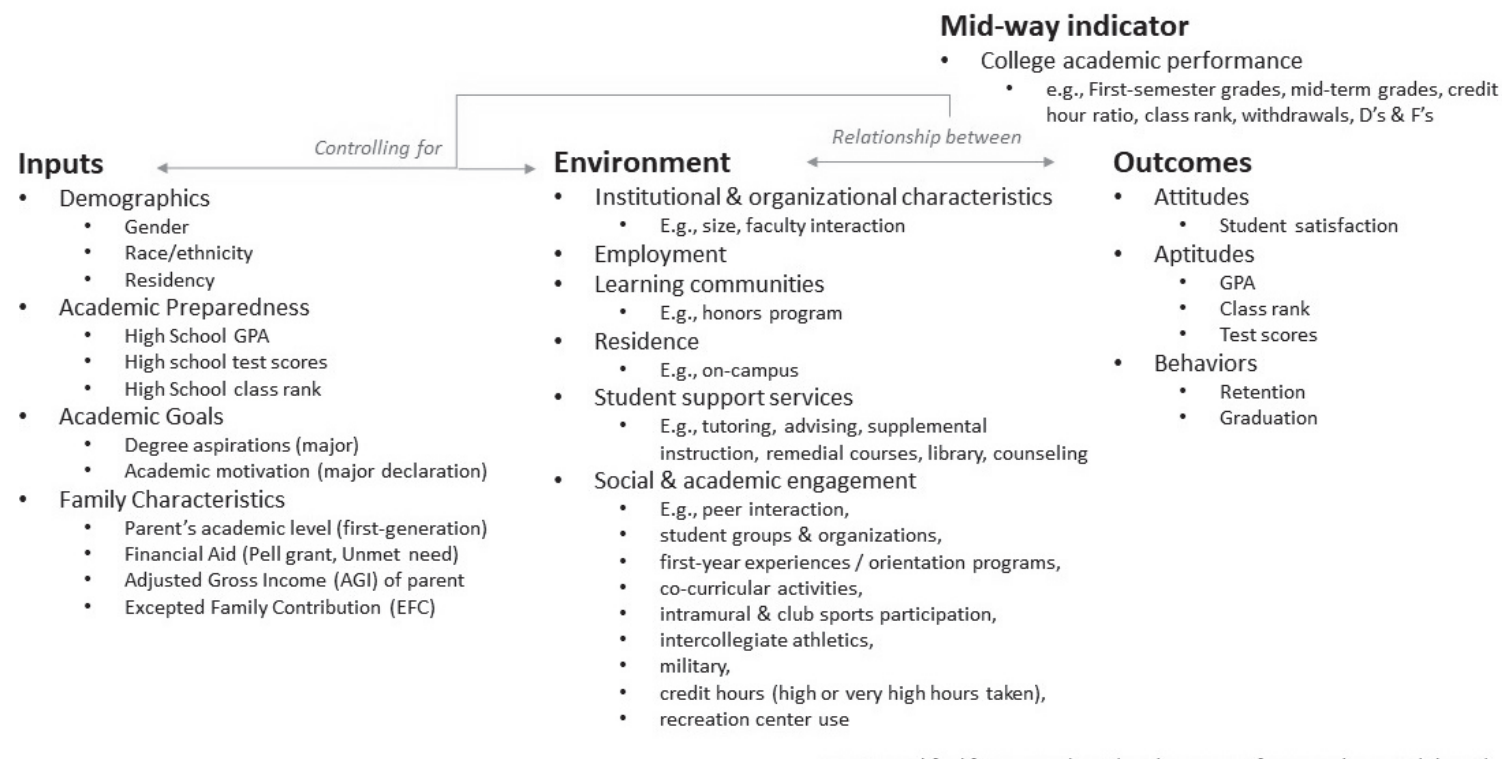

Figure modified from Astin (1984) with concepts from Mayhew et al. (2016).

Statistical models used to predict student persistence have some similarities and differences. Models predicting student persistence typically include various pre-enrollment inputs such as student demographics, academic preparedness, as well as family and income characteristics (Burke et al., 2017). Astin $(1975,1984,1993)$ asserted that key contributors include prior academic achievement, college academic performance, living on campus, and involvement in extracurricular activities. On-campus residence, however appeared weakly positively related to attainment (Pascarella \& Terenzini, 2005). Literature specifically highlights the positive impact of students having parents who had received a college degree, as well as various within-college experiences such as earning high grades, living on campus, having meaningful peer interactions and relationships, and experiencing overall social and academic integration and involvement (Mayhew et al., 2016). Intercollegiate athlete status and campus recreation facility usage have been used as surrogates for social engagement or involvement in extracurricular activities (Huesman et al., 2007, 2009; Roddy et al., 2017; Vasold, Deere, \& Pivarnik 2019; Vasold, Kosowski, \& Pivarnik, 2019). 


\section{Data and Methods}

This study analyzed census data for three cohorts of full-time, first-time undergraduate students from the Office of Institutional Research at the main campus of a public land-grant research university between 2014 and 2017 (i.e., Fall 2014-Spring 2015, Fall 2015-Spring 2016, and Fall 2016-Spring 2017, excluding summers). Full-time students were classified as those who took at least 12 credits in fall or spring semester. Institution-level census data enabled analysis of both participants and non-participants. Students' persistence from first-year fall to second-year fall is the key outcome variable for the study. The key predictor variable is an indicator for recreational facility (hereafter "facility") usage based on total visits from swipe card data at the institution's single facility over the first year, August through April. Students who had at least four visits per month were classified as users, and students who had less than one visit per month were classified as non-users. Students who used the facility infrequently (i.e. at least once per month but less than once a week) are excluded from analyses; benefits are unclear for this level of participation, and excluding this group allows for a clearer comparison of users and non-users. The number of visits was divided by nine months for students enrolled all year and four-and-ahalf months for students enrolled for one semester only. Although some universities offer students an option to pay for recreation facility membership (Danbert at al., 2014), other universities — such as the one in this study_-include membership fees in required student fees.

The choice of control variables used in this analysis was informed by the theoretical framework for student persistence posed in this paper (Figure 1), as well as what data sources were practically available. The primary outcome studied was retention, given the relevance of the theoretical framework and the importance of the outcome to the institution. Given limited 
availability of facility use data, graduation was not assessed. Figure 2 highlights the aspects of the student persistence conceptual model used in this analysis.

Specifically, we estimated a model of student persistence of the form

$$
\operatorname{Prob}\left(Y_{i t}=1 \mid D_{i}, A_{i t}, P_{i}, F_{i t}, E_{i t}\right)=\frac{e^{\beta_{0}+\beta_{1} D_{i}+\beta_{2} A_{i t}+\beta_{3} P_{i}+\beta_{4} F_{i t}+\beta_{5} E_{i t}}}{1+e^{\beta_{0}+\beta_{1} D_{i}+\beta_{2} A_{i t}+\beta_{3} P_{i}+\beta_{4} F_{i t}+\beta_{5} E_{i t}}}(1),
$$

where $Y_{i t}$ is an indicator for student $i$ 's persistence outcome in year $t, D_{i}$ is a vector of student demographics (sex, race/ethnicity, and state residency), $A_{i t}$ is a vector of academic measures (high school GPA, an indicator for having declared a major in the first term, and indicators for credit loads in of the first term attended in year $t), P_{i}$ is a measure of family characteristics (specifically, an indicator for first-generation status, which captures parents' educational background), $F_{i t}$ is a vector of financial variables (student $i$ 's unmet financial need in year $t$, expressed in thousands of dollars, and an indicator for having received a Pell Grant in year $t$ ), and $E_{i t}$ is a vector of environmental factors in year $t$ (indicators for residential locations, honors program participation, military affiliation, and intercollegiate athletics participation), and the $\beta$ 's are vectors of regression coefficients to be estimated.

Figure 2: Model of student persistence used in analysis

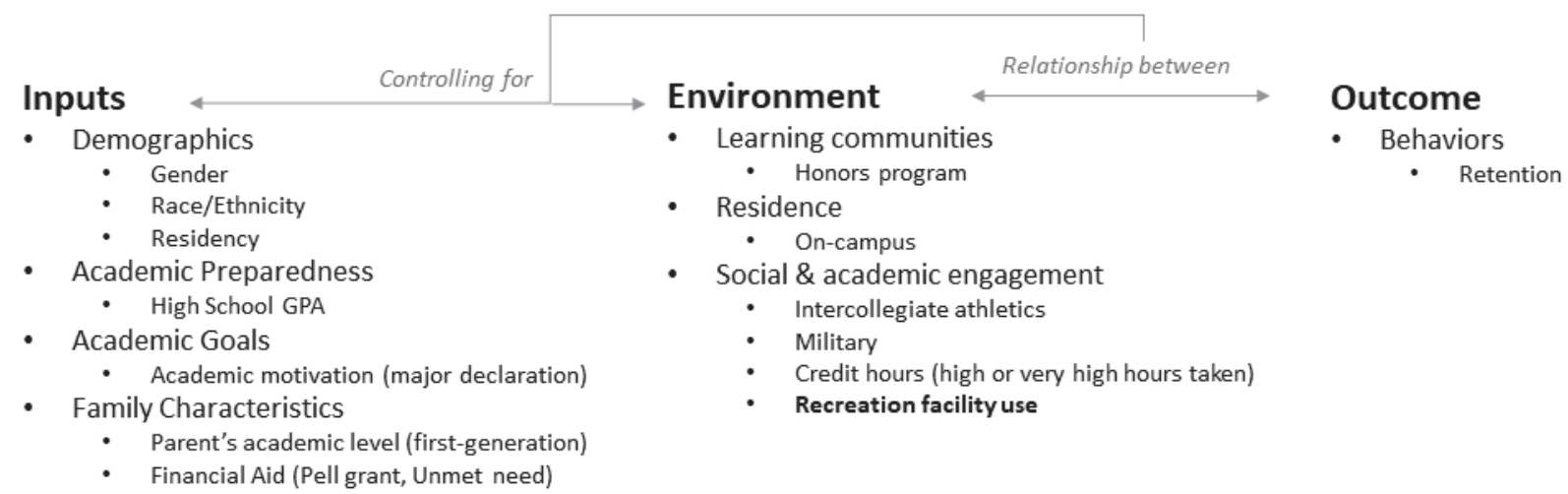

Figure modified from Astin (1984) with concepts from Mayhew et al. (2016). 
For academic preparedness, high school GPA was used instead of high school test scores because not all incoming students had ACT or SAT scores. Given research that indicated the value of early degree declaration (Leppel, 2001), authors included student degree declaration (i.e., by the end of the first term) as a measure of academic goals prior to college involvement. Credit hour indicators reflect high fall credit loads (16 or 17 credits) and very high credit loads (17.5 credits or more), relative to 15 or fewer credits. The model also included dummy variables for year to detect and absorb variation over time in the outcome variable or in the measurement of control variables. In addition, the initial model also included multiple groups for the race/ethnicity variable; given that no group variable was a significant predictor for all years, the race/ethnicity variable was aggregated in the final analysis in pursuit of greater statistical power. The unmet need variable was found to be a better measure than expected family contribution (EFC) or adjusted gross income (AGI), because those variables were not available for financially independent students at this institution.

Descriptive results of the sample indicate some significant differences between facility users and non-users. In comparison to non-users, facility users had a higher share of males, persons of color (POCs), and students living on campus, and had lower shares of in-state students, undecided majors, first-generation students, Pell Grant recipients, and intercollegiate athletes; they also had higher first-year retention (Table 1). Given large sample size, effect size (i.e., Cohen's d) was used to examine strength of relationship not dependent on p-value. Effect size of the differences between users and non-users was found to be moderate for students who were female and who live off campus, and small for in-state (for fee purposes), first-generation status, and first-year retention.

Table 1: Descriptive statistics for sample by recreational facility users and non-users for fulltime, first-time undergraduates, 2014-17 


\begin{tabular}{lcccc|ccc} 
& \multicolumn{3}{c}{$\begin{array}{c}\text { Logit sample } \\
(N=8,814)\end{array}$} & \multicolumn{3}{c}{$\begin{array}{c}\text { Matching sample } \\
(N=8,738)\end{array}$} \\
Variable & User & Non-user & Sig. & E. Size $~$ & User & Non-user & Sig. \\
\hline Female & 0.34 & 0.55 & $* * *$ & -.45 & 0.34 & 0.34 & \\
Person of color (POC) $\wedge$ & 0.17 & 0.14 & $* * *$ & .09 & 0.17 & 0.17 & \\
In-state (fee purposes) & 0.52 & 0.63 & $* * *$ & -.23 & 0.52 & 0.62 & $* * *$ \\
High school GPA & 3.46 & 3.47 & & -.03 & 3.46 & 3.45 & \\
Undecided major (first term) & 0.07 & 0.09 & $* *$ & -.08 & 0.07 & 0.09 & $* *$ \\
First-generation student & 0.19 & 0.26 & $* * *$ & -.15 & 0.19 & 0.19 & \\
Pell grant recipient & 0.28 & 0.34 & $* * *$ & -.14 & 0.28 & 0.28 & \\
Unmet need (in thousands) & 2.58 & 2.45 & & .03 & 2.58 & 2.32 & $*$ \\
Honors student & 0.15 & 0.16 & & -.02 & 0.15 & 0.17 & $*$ \\
Live off campus & 0.05 & 0.22 & $* * *$ & -.48 & 0.05 & 0.20 & $* * *$ \\
Intercollegiate athlete & 0.02 & 0.03 & $* *$ & -.06 & 0.02 & 0.04 & $* * *$ \\
Military student & 0.01 & 0.01 & & .02 & 0.01 & 0.01 & \\
Credit hours - high $\wedge \wedge$ & 0.40 & 0.39 & & .04 & 0.40 & 0.40 & \\
Credit hours - very high $\wedge \wedge$ & 0.11 & 0.10 & & .03 & 0.11 & 0.10 & \\
First-year retention & 0.83 & 0.76 & $* * *$ & .18 & 0.83 & 0.76 & $* * *$ \\
\hline
\end{tabular}

${ }^{*} \mathrm{p}<0.05, * * \mathrm{p}<0.01, * * * \mathrm{p}<0.001$

Note: Sample excludes infrequent users (1 per month up to $<1$ per week).

${ }^{\wedge}$ POC includes the following categories: Black (not Hispanic), Asian, Hispanic, American Indian or Alaskan Native, Native Hawaiian or Pacific Islander, Two or More Races, and Unknown. Model initially included categories for race/ethnicity variable. Given no category was a significant predictor for all years given low frequency, race/ethnicity variable was collapsed to a binary variable in final analysis.

$\wedge$ Credit hours high (16-17 hours /semester) and very high (17.5+ hours /semester).

$\sim$ Effect Size $=$ Cohen's $d$, where $0.2=$ small, $0.5=$ moderate, 0.8 large

The first two columns of Table 1 illustrate several differences between facility users and non-users. As a complementary approach, we also employed a matching technique intended to reduce baseline imbalance between users and non-users and consequently reduce dependence on modeling assumptions (Iacus et al., 2012). Specifically, we used coarsened exact matching to match students on sex, race/ethnicity, Pell Grant receipt, first-generation status, HS GPA category (below 3.1, 3.1 to below 3.5, 3.5 to below 4.0, and 4.0), and cohort (Iacus, et al., 
2012) $)^{1}$. The second panel of Table 1 illustrates that our matched sample exhibits balance between users and non-users on sex, race, high school GPA, first-generation status, and Pell Grant receipt. Including these factors as explicit controls in a regression model and matching on them at baseline represent complementary approaches to limiting the influence of factors unrelated to facility use, and we will report findings from both approaches. We estimated a version of equation (1) for all students in the matched sample as well as subgroups along each dimension of our matching strategy (i.e., female students, male students, POCs, non-POCs, students with higher high school GPA, students with lower high school GPA, Pell recipients, students who did not receive Pell, first-generation students, and non-first-generation students) in which we regressed the retention outcome on the facility use indicator only.

\section{Results}

\section{Retention by Facility Use}

Logistic regression for retention, controlling for all variables, demonstrates a significant relationship between first-year retention and recreational facility use; marginal effects at the means of other covariates are reported as a more practical means to interpret than odds ratios or logit coefficients (Table 2). Results suggest the facility users had 8.4 percentage points higher retention than non-users, holding other variables constant. Other significant covariates show high magnitudes: honors program participation (14.2 percentage points higher), intercollegiate athletic participation (13.6 percentage points higher), and each additional point of high school GPA (13.5 percentage points higher). Results also indicate a significant relationship between retention and very high credit hours (i.e., over 17.5) taken (6.6 percentage points higher). Results also suggest

\footnotetext{
${ }^{1}$ Iacus et al. (2012) demonstrate that coarsened exact matching outperforms other matching methods, including propensity score matching, in reducing sample imbalance, model dependence, estimation error, bias, and variance.
} 
significant negative association (i.e., 6.1 percentage points lower) with an undecided major at the start of the first term, as well as negative average marginal effects for first-generation status, Pell receipt, and each additional thousand dollars of unmet financial need.

Table 2: Logit regression results with marginal effect for first-year retention of full-time, firsttime undergraduates, 2014-5 through 2016-17

\begin{tabular}{lrrl} 
Variable & Margins & SE & Sig. \\
\hline Female & 0.024 & 0.009 & $* *$ \\
Person of color (POC) & 0.001 & 0.011 & \\
In-state (fee purposes) & 0.009 & 0.009 & \\
High school GPA & 0.135 & 0.009 & $* * *$ \\
Undecided major (first term) & -0.061 & 0.013 & $* * *$ \\
First generation student & -0.030 & 0.009 & $* *$ \\
Pell recipient & -0.049 & 0.009 & $* * *$ \\
Unmet need (in thousands) & -0.009 & 0.001 & $* * *$ \\
Honors student & 0.142 & 0.020 & $* * *$ \\
Live off campus & 0.012 & 0.012 & \\
Intercollegiate athlete & 0.136 & 0.031 & $* * *$ \\
Military student & 0.015 & 0.036 & \\
Credit hours - high $(16-17$ hrs.) & 0.012 & 0.009 & \\
Credit hours - very high $(17.5+$ hrs.) & 0.066 & 0.018 & $* * *$ \\
Recreational facility use & 0.084 & 0.009 & $* * *$ \\
\hline$N=8,814 ;$ Pseudo $R^{2}=0.123 ; * p<0.05, * * p<0.01, * * *$ & $*<0.001$
\end{tabular}

Notes: Sample excludes infrequent users ( 1 per month up to $<1$ per week). Dummy variables for year used but not reported. Logit regression coefficients and odds ratios are available from the authors upon request.

\section{Matching Approaches}

As illustrated in Table 1, matching users and non-users on baseline characteristics is a complementary approach to estimating the relationship between facility use and retention that relies on the assumption of greater comparability between facility users and non-users prior to estimation. Results from this approach for all students suggest that facility users had 7.1 percentage points higher retention than non-users, which is smaller but still statistically significant (Table 3). We also produced estimates for each student subgroup included in our 
matching strategy, and subgroup estimates suggest that Pell recipients had a higher marginal effect of use than non-Pell recipients had, first-generation students had a higher marginal effect than non-first-generation students had, and students with below a 3.5 high school GPA had a higher marginal effect than students with a 3.5 or higher GPA had (Table 3). In Figure 3, we report the predicted overall retention rates for all students and subgroups by facility use, and the gaps between non-user and user bars for a subsample in Figure 3 illustrate the marginal effects presented in Table 2.

Table 3: Logit regression results with marginal effects of recreation facility use for first-year retention of full-time, first-time undergraduates in matched samples, 2014-15 through 2016-17

\begin{tabular}{|c|c|c|c|c|c|c|}
\hline Variable & Female & Male & Not POC & POC & Not Pell & Pell \\
\hline $\begin{array}{l}\text { Recreational } \\
\text { facility use }\end{array}$ & $\begin{array}{c}0.057 * * * \\
(0.014)\end{array}$ & $\begin{array}{c}0.078 * * * \\
(0.013)\end{array}$ & $\begin{array}{c}0.072 * * * \\
(0.011)\end{array}$ & $\begin{array}{l}0.063 * \\
(0.030)\end{array}$ & $\begin{array}{c}0.057 * * * \\
(0.011)\end{array}$ & $\begin{array}{c}0.105 * * * \\
(0.021)\end{array}$ \\
\hline Observations & 4,118 & 4,620 & 7,481 & 1,257 & 5,993 & 2,745 \\
\hline Variable & & $\begin{array}{c}\text { All } \\
\text { Students }\end{array}$ & $\begin{array}{c}\text { Not First- } \\
\text { Gen }\end{array}$ & $\begin{array}{l}\text { First- } \\
\text { Gen }\end{array}$ & $\begin{array}{l}3.5 \text { or } \\
\text { Higher }\end{array}$ & $\begin{array}{c}\text { Below } \\
3.5\end{array}$ \\
\hline $\begin{array}{l}\text { Recreational } \\
\text { facility use }\end{array}$ & & $\begin{array}{c}0.071 * * * \\
(0.010)\end{array}$ & $\begin{array}{c}0.062 * * * \\
(0.011)\end{array}$ & $\begin{array}{c}0.108 * * * \\
(0.025)\end{array}$ & $\begin{array}{l}0.022 * \\
(0.010)\end{array}$ & $\begin{array}{c}0.124 * * * \\
(0.017)\end{array}$ \\
\hline Observations & & 8,738 & 6,733 & 2,005 & 4,773 & 3,965 \\
\hline
\end{tabular}

Standard errors in parentheses; $* p<0.05, * * p<0.01, * * * p<0.001$

Notes: Sample excludes infrequent users ( 1 per month up to $<1$ per week). Person of color (POC) includes the following categories: Black (not Hispanic), Asian, Hispanic, American Indian or Alaskan Native, Native Hawaiian or Pacific Islander, Two or More Races, and Unknown. Coarsened exact matching used to match students on sex, race/ethnicity, Pell Grant receipt, first-generation student status, HS GPA category (below 3.1, 3.1 to below 3.5, 3.5 to below 4.0, and 4.0), and cohort.

Figure 3: Predicted first-year retention of full-time, first-time undergraduates in matched samples by key student characteristics and recreation facility use, 2014-15 through 2016-17 

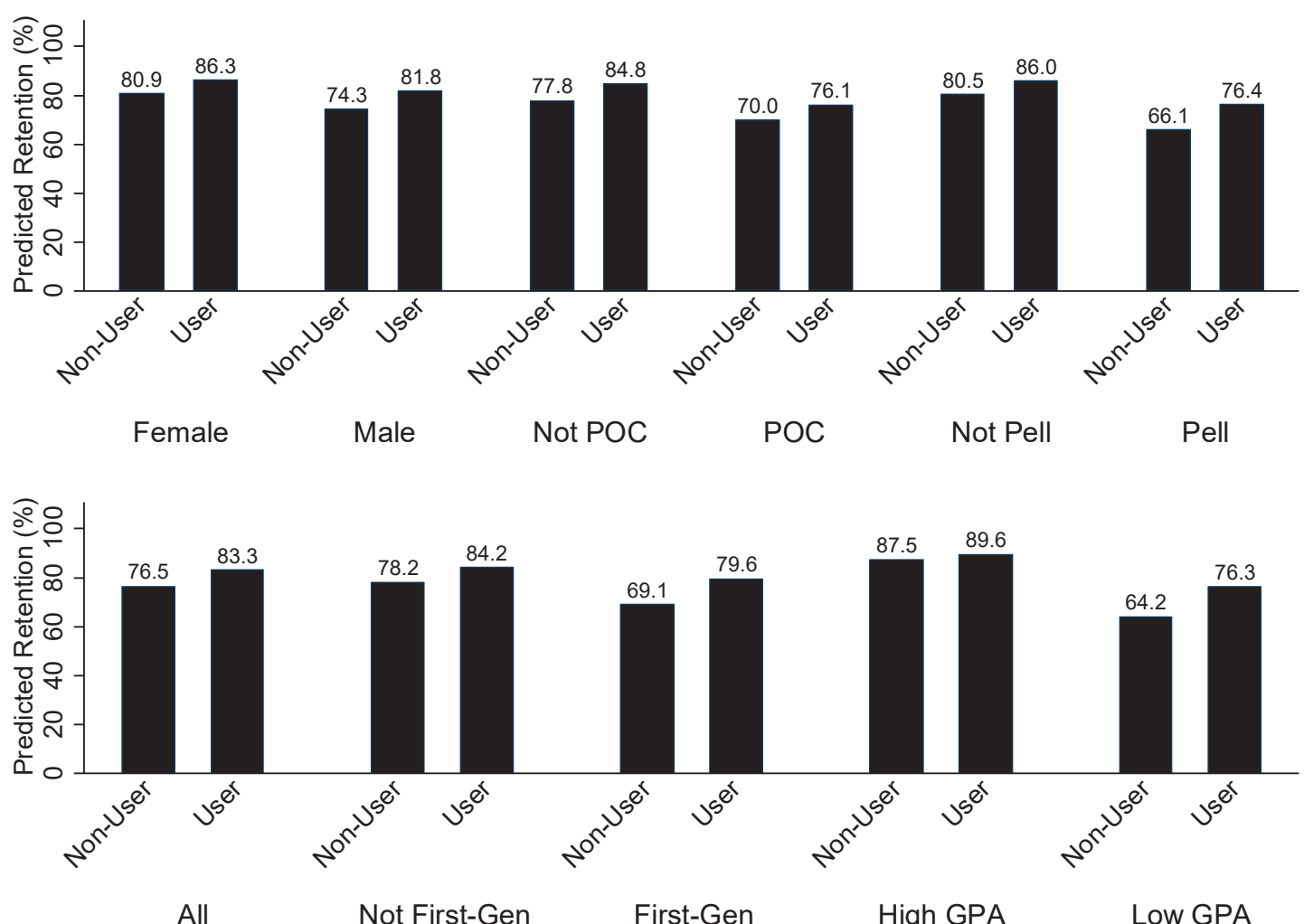

Notes: Person of color (POC) includes the following categories: Black (not Hispanic), Asian, Hispanic, American Indian or Alaskan Native, Native Hawaiian or Pacific Islander, Two or More Races, and Unknown. Coarsened exact matching used to match students on sex, race/ethnicity, Pell Grant receipt, first-generation student status, HS GPA category (below 3.1, 3.1 to below 3.5, 3.5 to below 4.0, and 4.0), and cohort.

Without the benefit of plausibly random assignment of facility usage to groups of users and non-users, results may be biased by systematic and unobserved differences between users and non-users (Mayhew et al., 2016). Users, for example, may have more motivation, time management, and familiarity with campus resources, or time not working for pay, and we do not capture these factors in our dataset (Fosnacht, et al., 2018; Logan et al., 2016). If any of these factors is positively associated with retention, which is likely, then estimates of the association between facility use and retention could be biased upward. Further, approaches like nearestneighbor matching that rely exclusively on observed differences to account for selection still 
may be subject to bias from these unobserved factors (Vasold, Kosowski, \& Pivarnik, 2019; LaLonde, 1986; Smith \& Todd, 2005).

We capitalize on different physical proximity of residence halls to the facility to introduce another check of the robustness of our findings. Specifically, we capitalize on an assignment process to residence halls that may leave some but not all students with their desired choice of residence hall, and some but not all students exogenously closer to the facility. The institution under study has two campus locations (i.e., near facility and far from facility), topographically separated by a mile and a half distance and an elevation change of almost 200 vertical feet. In our full sample, 31.8 percent of students who live in the campus near facility are facility users, and only 17.1 percent of students who live in the campus far from facility are facility users. First-time undergraduate students can live in either campus location, but the campus location far from the facility is more popular and requests to live there exceed residence hall capacity. Some students can end up living in the campus near the facility even if they indicated a preference for the campus far from the facility. Alternatively, some students can end up living in closer proximity (i.e., in the campus near) to the facility even after indicating preference for the campus far from the facility, so they do not opt into this proximity.

Our rationale for this robustness check is to supplement census data with housing data for two years of our sample to compare students who indicated preference for the campus far from the facility, where some actually lived in the campus near the facility and some lived in the campus far from the facility. We utilize coarsened exact matching to match students who expressed preference for living in the campus far from the facility on sex, race, cohort, high school GPA categories, Pell Grant receipt, and first-generation status, where in this case "treated" students lived near the facility and "control" students lived far from the facility. We 
then estimated equation (1) using the matched sample and rely on the sample of all remaining students with covariates given the smaller sample size. We regard assignment to live in the campus near the facility as the treatment for matching, where such assignment represents closer physical proximity to the facility. Table 4 illustrates characteristics of students after matching. Among students who indicated preference for living far from the facility, students who were assigned closer to the facility were statistically significantly more likely to be facility users.

Table 4: Means by residence hall proximity to recreation facility for full-time, first-time undergraduates in matched housing sample, 2015-16 through 2016-17

\begin{tabular}{|c|c|c|c|}
\hline Variable & $\begin{array}{l}\text { Closer to } \\
\text { facility }\end{array}$ & $\begin{array}{l}\text { Far from } \\
\text { facility }\end{array}$ & Sig. \\
\hline Female & 0.51 & 0.51 & \\
\hline Person of color (POC) & 0.17 & 0.17 & \\
\hline In-state (fee purposes) & 0.53 & 0.59 & $*$ \\
\hline High school GPA & 3.50 & 3.50 & \\
\hline Undecided major (first term) & 0.05 & 0.08 & $*$ \\
\hline First-generation student & 0.23 & 0.23 & \\
\hline Pell Grant (federal aid) & 0.36 & 0.36 & \\
\hline Unmet need (in thousands) & 3.59 & 3.00 & \\
\hline Honors student & 0.23 & 0.26 & \\
\hline Intercollegiate athlete & 0.02 & 0.01 & \\
\hline Military student & 0.00 & 0.01 & \\
\hline Credit hours - high (16-17 hrs.) & 0.36 & 0.42 & $*$ \\
\hline Credit hours - very high $(17.5+$ hrs. $)$ & 0.12 & 0.09 & \\
\hline Recreational facility use & 0.51 & 0.30 & $* * *$ \\
\hline
\end{tabular}

Notes: Coarsened exact matching used to match students on sex, race/ethnicity, Pell Grant receipt, first-generation student status, HS GPA category (below 3.1, 3.1 to below 3.5, 3.5 to below 4.0, and 4.0), and cohort.

Table 5 illustrates results from a logit regression model of retention on the same set of covariates presented in Table 2 plus an indicator for campus assignment. ${ }^{2}$ In particular, facility

${ }^{2}$ Authors also estimated the main model for years 2015-16 and 2016-17 only, with a control for specific on-campus location instead of off-campus residence (because only on-campus students submit housing preferences, and the matching analysis is limited to on-campus students), and 
users' probability of persisting to the next year is 13.5 percentage points higher than non-users' probability of persisting, conditional on those covariates. As in Table 4, this finding proceeds from a matched sample of students who exhibit balance on sex, race, high school GPA, firstgeneration student status, and Pell Grant receipt. More importantly, Table 4 reflects that students assigned to the campus closer to the facility were significantly more likely to be users, and all students in this sample communicated a preference to live on the other campus. This introduces a possibility that at least some students in this sample would not have been facility users if they lived farther from the facility but became users by virtue of their unexpected closer proximity.

Table 5: Logit regression results with marginal effects for first-year retention of full-time, firsttime undergraduates in matched housing sample, 2015-16 through 2016-17

\begin{tabular}{|c|c|c|c|}
\hline Variable & Margins & SE & Sig. \\
\hline Female & 0.043 & 0.018 & * \\
\hline Person of color (POC) & 0.006 & 0.026 & \\
\hline In-state (fee purposes) & 0.006 & 0.019 & \\
\hline High school GPA & 0.144 & 0.020 & $* * *$ \\
\hline Undecided major (first term) & -0.015 & 0.031 & \\
\hline First generation student & -0.039 & 0.022 & \\
\hline Pell Grant recipient & -0.017 & 0.020 & \\
\hline Unmet need (in thousands) & -0.007 & 0.002 & $* * *$ \\
\hline Honors student & 0.114 & 0.029 & $* * *$ \\
\hline Campus closer to facility & -0.045 & 0.019 & * \\
\hline Intercollegiate athlete & 0.176 & 0.139 & \\
\hline Military student & 0.009 & 0.087 & \\
\hline Credit hours - high (16-17 hrs. /semester) & -0.025 & 0.018 & \\
\hline Credit hours - very high $(17.5+\mathrm{hrs} . /$ semester $)$ & 0.019 & 0.034 & \\
\hline Recreational facility use ${ }^{\wedge}$ & 0.135 & 0.019 & $* * *$ \\
\hline
\end{tabular}

\section{Limitations}

without any matching adjustments or restrictions on housing preferences. Results were qualitatively similar to those in Table 2 , available from authors upon request. 
The preceding robustness check remains subject to some limitations. First, the treatment in this assignment process is proximity to the facility, rather than facility usage itself, so students who live far from the facility still might use the facility. This does not eliminate potential concerns about unobserved factors like time working outside school, awareness of campus facilities, time management, or motivation becoming confounded with the retention outcome, but this subsample should include a higher proportion of students exogenously assigned to be closer to the facility who become users by virtue of that proximity. As one illustration of the results in Table 5, students closer to the facility who are users have a predicted retention rate of 83.1 (conditional on all other model variables), compared to 76.5 for non-users far from the facility and 73.0 for non-users closer to the facility. Second, we did not illustrate results for different student subgroups using the matching approach presented in Tables 4 and 5 given the smaller number of students for whom we had housing preferences and eventual assignments. Within the 2,654 students in that overall sample, we believed some of the subgroups featured in Table 3 had too few students to generate subgroup-specific results in which we could be confident. Ultimately, this robustness check introduces a new source of plausibly exogenous variation in assignment to comparatively close proximity to a student recreational facility and does not overturn evidence from Tables 2 and 3 of a positive and statistically significant relationship between facility usage and retention.

Beyond the considerations of selection bias and potential selection on unobserved variables, additional limitations exist. First, card swipe data are imperfect measures of facility usage. While card swipe data exist for an institution-wide census of students, have a high degree of accuracy, and can be linked with other student academic and demographic records, card swipes may reflect facility visits for nothing more than a shower and do not reflect other 
activities like outdoor recreation, club or intramural sports participation, or usage of fitness equipment in residence halls or off-campus apartments. The present study also classified students as enrolled for nine (two semesters) or four-and-a-half months (one semester). However, if students only attended for part of a semester, usage measures that assumed students attended all months of that semester would underestimate the number of visits per month for months each student actually attended. Future research could introduce students' specific withdrawal dates into the calculation of usage rates.

Finally, additional limitations exist with respect to variables that were unavailable or featured measurement issues. As in Figure 1, academic outcomes including postsecondary GPA and degree completion are relevant, but we did not study them, and we identify this as important room for future research. High school GPA measures included as covariates were not normalized across high schools, so some students with high values for high school GPA might have attended lenient high schools rather than developed extensive academic preparation. ${ }^{3}$ Given Robbins et al.'s (2004) finding of psychological and study skill factors (e.g., academic motivation) to be more important than socioeconomic status, standardized test scores, and GPA in predicting colleges outcomes, future research might include additional measures of study skills and selfregulation. Card swipe data on access to resources like libraries or teaching and learning centers might supplement data on access to recreational facilities as additional proxies for student time use or as primary predictors of central outcomes.

\section{Discussion}

\footnotetext{
${ }^{3}$ We replicated the results in Table 2 with concorded SAT/ACT scores instead of high school GPA and yielded similar results with over 3,000 fewer observations. Full results are available from the authors upon request.
} 
This study advances previous studies linking retention with recreation that used descriptive statistics (Belch et al., 2001; Danbert et al., 2014; McElveen \& Ibele, 2019), as well as studies that used statistical models with multiple covariates (Bell \& Chang, 2017; Brock et al., 2015; Huesman et al., 2007, 2009; Kampf \& Teske, 2013; Leppel, 2005; Michael et al., 2017; Vasold, Deere, \& Pivarnik 2019; Vasold, Kosowski, \& Pivarnik, 2019). This study presents a statistical analysis with extensive controls to quantify the relationship between facility use and first-year retention in the presence of other factors that might be driving student persistence, offering conceptual models (Figures $1 \& 2$ ) that can inform the assessment of a program's contributions to retention goals. The study's findings support previous research identifying a positive relationship between both social involvement and co-curricular measures and academic success (Kuh, et al., 2008; Light 1992; Pascarella \& Terenzini, 2005; Robbins et al., 2004), specifically reinforcing that facility use has a significant relationship with first-year persistence (Huesman et al., 2009).

This study introduces two matching approaches, including one in which students relinquish full control over housing assignments and live different distances from the recreation facility. Estimates of any relationship between facility use and retention without random assignment are a mix of any causal effect of recreation center usage on retention plus any potential confounding with characteristics that are associated with selection into usage but not included in our models, like time working outside school, awareness of campus facilities, time management, or motivation. Authors introduced one matching approach that attempts to isolate variation in usage more narrowly around students who had closer physical proximity to recreational space not by choice, potentially limiting bias from selection into facility use based entirely on observable characteristics (Vasold, Kosowski, \& Pivarnik, 2019). The net effect on 
retention from any future expansion of recreational opportunities would not come from students who, by virtue of their motivation or existing buy-in into the campus community, would use the existing facility already. The effect would come instead from students who would be brought into using the facility — or using the facility more - because of characteristics like a new level of convenience or service offerings. We have argued that students who use the existing facility because they unexpectedly live close to it would offer a good sense of the outcomes to be expected for this group of students.

Results show a positive and significant relationship between facility use and first-year retention in full-time, first-time undergraduate students, including 7.1 to 8.4 percentage points higher retention for facility users versus non-users, controlling for student demographics, academic preparedness, academic goals, family characteristics, and environmental factors. Both matching approaches support the significance of the facility use variable. Subsample analysis based on variables used for matching suggests the biggest marginal differences between users and non-users were for students who were Pell Grant recipients, were first-generation, and had lower high school GPA. We identify potential for evidence of heterogeneous benefits of facility use across student characteristics as one important direction for future research, and we note one possible direction below.

\section{Implications for Practice}

Scope of benefits of campus resources. This research represents only a portion of a given campus resource's potential value for four reasons. First, this study presents results using data from "business as usual"; campus recreation programs at this institution did not intentionally attempt to increase institutional retention, as outdoor orientation programs have done (Andre, et al., 2017; Bell \& Chang, 2017; Gass, 1987, 1990; Michael, et al., 2017). Second, 
the study's card swipe data do not include all aspects of campus recreation, such as intramural and club sports, personal training, group fitness, aquatics, adaptive, outdoor, and special events (McFadden \& Stenta, 2015).

Third, use of a campus recreation facility may have an influence on outcomes beyond retention and grades, such as ability to develop friendships, ability to multi-task, communication skills, fun and enjoyment, group cooperation, meeting new people, multi-cultural awareness, physical fitness, problem solving, relieving stress, respect for others, sense of belonging, time management, and weight loss/control (Forrester, 2014).

Finally, this research only examined full-time, first-time undergraduate students, a portion of the university that represents less than 10 percent of both undergraduate and total students in this study population. Outside of this group of full-time, first-time undergraduate students, upwards of 60 percent of students who leave U.S. colleges and universities without completing degrees drop out later than the first year (Ryan, 2004; Shapiro et al., 2014). Authors also note positive estimates of relationships between retention and experiences like honors program participation and intercollegiate athletic status, where these programs reach a relatively small share of students on campus. Campus recreation, however, is a campus resource more in line with a writing center, library, or teaching and learning center, providing access for all members of the university, such that expansions in capacity for these resources have the potential to reach all students. Given that many powerful predictors of retention are fixed (Huesman et al., 2009), institutions should note what they can influence, such as the relationship between student persistence and facility use.

Introduction of intentional programming. Beyond "business as usual", campus recreation facilities might introduce programming and resources focused more specifically on 
retention. Programs could be developed to intentionally improve institutional retention or specific elements found to increase retention such as positive peer interactions, student involvement in the university, interaction with faculty/staff, academic related skills, academic self-efficacy, and academic goals (Astin, 1975, 1977, 1993; Mayhew, et al., 2016). Campus recreation could also engage students through school-specific programming to foster peer-group and co-curricular development. Belch et al. (2001) suggested campus recreation to play a key role in fall orientation, hosting events, and teaching about opportunities to connect and belong. Programming could include workshops, programs, or even semester-long classes to promote time management, study habits, leadership, problem solving and coping, and communication skills, or even to inform students about the locations, hours, and program offerings of recreation facilities and other campus resources located on campus along with messaging about the benefits of engagement for retention and academic success. Programming development should account for retention and sense of belonging differences across race, first-generation, and income levels (Gopalan \& Brady, 2019), especially given this study's preliminary stratified findings suggest that groups at higher risk of departure have higher marginal effects of recreation facility use.

Strategic facility and program placement. Administrators should strategically develop residential and campus recreation opportunities within proximity of students in order to maximize students' potential to benefit from these resources (Huesman et al., 2009). With respect to promoting retention, administrators should identify students at risk for dropping out of their programs or leaving their institutions and where those students live, and then ensure those students have recreational opportunities created especially for them and have close access to physical campus facilities. (Our data suggested that students who lived closer to the main recreational facility were significantly more likely to be regular users, even controlling for high 
school GPA, financial need, first-generation status, and other factors.) Students with physical or mobility disabilities should also be included in this group, given that these students can benefit from facility use, new facilities should be designed with accommodations in mind, and existing facilities may be updated if they are not already fully accessible (Rimmer et al., 2017). In addition, campus planners may need to pursue different programming measures to provide accommodations for off-campus and online students or recognize that any potential retention benefits from these facilities will accrue primarily among students living on campus (Seidman, 2012).

\section{Implications for Research}

Use of card swipe data. Using actual behavior via swipe card information or other means can make a useful contribution to retention literature. Some research, for example, has specifically explored library use patterns' relationship to GPA (Renaud, et al., 2015). Institutions are applying predictive analytics to student success initiatives to identify at-risk students, but there is a gap in research using student engagement data in predictive models (Burke et al., 2017). Using actual student behaviors can help universities better understand and predict institutional retention; engagement measures, for example, could be added to prediction models to improve identification of at-risk students, explore social networks, and predict retention outcomes (Blue, 2018; Jutting, 2013).

Contribution to definition of user. Previous research in campus recreation examined differences in academic outcomes by different user categories and definitions of users (Belch, et al. 2001; Forrester, 2014; Huesman et al., 2007, 2009; Kampf, \& Teske, 2013; Leppel, 2005; Roddy et al., 2017). Although most card swipe research has classified users as those who used the facility once, (Belch et al., 2001; Kampf, \& Teske, 2013; Roddy et al., 2017), authors 
challenge counting single-entry visitors as users, as did Leppel (2005). The present study defined users as those who visited at least once per week. This method is supported by industry survey research (Forrester, 2014, 2015), as well as a study that found first-year students who used campus recreation facilities at least 25 times a semester (i.e., slightly over once per week) significantly increased predicted probability of first-year retention (Huesman et al., 2009). Students who used the facility infrequently (i.e. at least once per month but less than once a week) were excluded from analyses in this study; benefits were unclear for this level of use, and excluding this group allows for a clearer comparison of users and non-users. Authors suggest eliminating the infrequent user group only in the case when the analysis compares users and nonusers, calculating binary differences, for example, in retention. User groups (i.e., categorical data) remain appropriate when comparing differences in user types. Given inconsistent definitions of users across previous studies (Belch et al., 2001; Forrester, 2014, 2015; Huesman et al., 2007, 2009; Kampf, \& Teske, 2013; Roddy et al., 2017; Leppel, 2005; Mayers et al., 2017; Zizzi et al., 2004), future research should examine the definition of a user and user groups within a statistical modeling framework, using at least a multi-variate approach to attempt to account for other additional determinants of student outcomes. How practitioners and researchers define participants could be explored within other higher education facilities or programs like library use or tutoring, perhaps constructing variables that indicate whether a student participated several times or often — as opposed to never or once (Leppel, 2005).

Additional data sources. Although facility visits with card swipe access are quantified, the variable does not include recreation that occurs outside of the facility, nor represent the quality or duration of the visit. Future research could include observational or qualitative methods to quantify or qualify use, examining the association between facility activity usage 
types and academic outcomes. Other studies could also include independently or collectively examining the impact of other types of campus recreation, beyond facility use, including intramural and club sports programs (Kampf \& Teske, 2013; McElveen and Ibele 2019; Vasold, Deere, \& Pivarnik, 2019; Vasold, Kosowski, \& Pivarnik, 2019), as well as group fitness, outdoor recreation, or special event participation. Analysis could also specifically assess the impact of employment with campus recreation (Kampf \& Teske, 2013).

In addition, the authors recognize a need for longitudinal student analysis to determine involvement levels and academic benefits through degree completion (Huesman et al., 2009; Seidman, 2012; Vasold, Deere, \& Pivarnik, 2019), specifically examining the relationship between campus recreation and retention beyond the first year. Finally, to allow for comparability and reliability, research should focus on student-level analysis from multiple institutions (Mayhew et al., 2016), to examine the relationship between campus recreation and academic outcomes across institutions with different facilities and programs.

Program assessment. Departmental initiatives to improve institutional retention need program research and assessment to "endure over time ... [and]...provide empirical evidence that resources committed to them are an investment that yields long-term benefits to the institution" (Tinto, 2006, p.10). Lack of research and assessment could be problematic; if departments lack capacity to assess their effectiveness, university administrators may view programs like campus recreation as beneficial, yet ancillary to the academic success and retention of students (Danbert, et al. 2014; Jacob, et al., 2018). Within institutions, campus departments and programs need capacity to collect and analyze data to not only know who they serve but assess the efficacy of new programs and facilities. 
The distance from students' residences to campus facilities may be predictive of students' likelihood of using the facilities, and this information can be incorporated into evaluations of program efficacy, as in the present study. This information will be especially useful for program evaluation purposes on campuses in which housing assignments are randomly allocated or oversubscribed and students may not receive their first choice. Beyond housing assignments, random assignment of outreach efforts like facility tours, information sessions, or fee waivers to first-year seminars, orientation sessions, or course sections would provide a rigorous opportunity to evaluate the impact of the outreach on card swipes to the featured facilities as well as longer-term outcomes, and any such assessment should be intentional about sampling across sex, race, and socioeconomic status to evaluate the benefits of recreation participation in general and specifically for students across each of these groups.

\section{Conclusion}

Although this study provides evidence of the relationship between campus recreation participation and academic outcomes, findings represent only a small portion of potential mechanisms. Replicating the study across other institutions, incorporating other covariates, or using different use group definitions may change the magnitude of results. Even small differences in retention, however, especially at small, tuition-driven colleges, can have practical significance (Bell \& Chang, 2017, p.67). 


\section{References}

Andre, E. K., Williams, N., Schwartz, F., \& Bullard, C. (2017). Benefits of campus outdoor recreation programs: A review of the literature. Journal of Outdoor Recreation, Education and Learning, 9(1), 15-25. https://doi.org/10.18666/jorel-2017-v9-i1-7491

Astin, A. W. (1975). Preventing students from dropping out. Jossey-Bass.

Astin, A. W. (1984). Student involvement: a developmental theory for higher education. Journal of college student personnel, 25(4), 297-308.

Astin, A. W. (1993). What matters in college: Four critical years revisited. Jossey-Bass.

Belch, H.A., Gebel, M., \& Maas, G.M. (2001). Relationship between student recreation complex use, academic performance, and persistence of first-time freshman. NASPA Journal, $38(2), 254-268$.

Bell, B. (2006). Wilderness orientation: Exploring the relationship between college orientation programs and social support. Journal of Experimental Education, 29(2), 145-167. https://doi.org/10.1177/105382590602900206

Bell, B. \& Chang, H. (2017). Outdoor orientation programs: A critical review of program impacts on retention and graduation. Journal of Outdoor Recreation, Education, and Leadership, 9(1), 56-68. https://doi.org/10.18666/jorel-2017-v9-i1-7501

Blue, A. (2018, March 7). Researcher looks at 'digital traces' to help students. UA News. https://uanews.arizona.edu/

Bransberger, P., \& Michelau, D. K. (2016). Knocking at the college door: Projections of high school graduates. Western Interstate Commission for Higher Education. https://knocking.wiche.edu/reports 
Brock, M., Carr, J.W., \& Todd, M. K. (2015). An examination of campus recreation usage, academic performance, and selected health indices of college freshmen. Recreational Sports Journal, 39(1), 27-36. https://doi.org/10.1123/rsj.2014-0061

Burke, M., Parnell, A., Wesaw, A., \& Kruger, K. (2017). Predictive analysis of student data: A focus on engagement and behavior. NASPA-Student Affairs Administrators in Higher Education. https://www. naspa.org/images/uploads/main/PREDICTIVE_FULL_4-7-

\section{7_DOWNLOAD.pdf}

Chen, R. (2012). Institutional characteristics and college student dropout risks: A multilevel event history analysis. Research in Higher Education, 53, 487-505. https://doi.org/10.1007/s11162-011-9241-4

Danbert, S. J., Pivarnik, J. M., McNeil, R. N., \& Washington, I. J. (2014). Academic success and retention: The role of recreational sports fitness facilities. Recreational Sports Journal, 38(1), 14-22.

Forrester, S. (2014). The benefits of campus recreation. Corvallis, OR: NIRSA. https://nirsa.net/nirsa/wp-content/uploads/Benefits_Of_Campus_RecreationForrester_2014-Report.pdf

Forrester, S. (2015). Benefits of collegiate recreational sports participation: Results from the 2013 NASPA assessment and knowledge consortium study. Recreational Sports Journal, 39(1), 2-15. https://doi.org/10.1123/rsj.2015-0005

Fosnacht, K., McCormick, A., \& Lerma, R. First-year students’ time use in college: A latent time use analysis. Research in Higher Education, 59(7), 958-978. https://doi.org/10.1007/s11162-018-9497-z 
Gass, M. A. (1987). The effects of a wilderness orientation program on college students. Journal of Experiential Education, 10(2), 30-33. https://doi.org/10.1177/105382598701000208

Gass, M. A. (1990). The longitudinal effects of an adventure orientation program on the retention of students. Journal of College Student Development, 31(1), 33-38.

Gass, M. A., Garvey, D. E., \& Sugerman, D. A. (2003). The long-term effects of a first-year student wilderness orientation program. Journal of Experiential Education, 26(1), 34-40. https://doi.org/10.1177/105382590302600106

Gopalan, M., \& Brady, S. T. (2019). College students' sense of belonging: A national perspective. Educational Researcher. OnlineFirst. https://doi.org/10.3102/0013189X19897622

Henchy, A. (2011). The influence of campus recreation beyond the gym. Recreational Sports Journal, 35(2), 174-181. https://doi.org/10.1123/rsj.35.2.174

Huesman Jr, R. L., Brown, A. K., Lee, G., Kellogg, J. P., \& Radcliffe, P. M. (2007). Modeling Student Academic Success: Does Usage of Campus Recreation Facilities Make a Difference?. Paper presented at The National Symposium on Student Retention, WI.

Huesman, R. L., Brown, A. K., Lee, G., Kellogg, J. P., \& Radcliffe, P. M. (2009). Gym bags and mortarboards: Is use of campus recreation facilities related to student success? NASPA Journal, 46(1), 50-71. https://doi.org/10.2202/1949-6605.5005

Iacus, S. M., King, G., \& Porro, G. (2012) Causal inference without balance checking: Coarsened exact matching. Political Analysis, 20(1), 1-24. https://doi.org/10.1093/pan/mpr013 
Jacob, B., McCall, B., \& Stange, K. (2018). College as country club: Do colleges cater to students' preferences for consumption? Journal of Labor Economics, 36(2), 309-348. https://doi.org/10.1086/694654

Jutting, C. (2016, August 3). Universities are tracking their students. Is it clever or creepy? The Guardian. https://www.theguardian.com

Kampf, S., \& Teske, E. J. (2013). Collegiate recreation participation and retention. Recreational Sports Journal, 37(2), 85-96. https://doi.org/10.1123/rsj.37.2.85

Kirshstein, R. J., \& Kadamus, J. A. (2012). Climbing Walls and Climbing Tuitions. Delta Cost Project at American Institutes for Research. https://eric.ed.gov/?id=ED541212

LaLonde, R. J. (1986). Evaluating the econometric evaluations of training programs with experimental data. American Economic Review, 76(4), 604-620.

Leppel, K. (2001). The impact of major on college persistence among freshmen. Higher Education, 41(3), 327-342. https://doi.org/10.1023/a:1004189906367

Leppel, K. (2005). The impact of sport and non-sport activities on college persistence of freshmen. Journal of College Student Retention: Research, Theory \& Practice, 7(3), $165-$ 188. https://doi.org/10.2190/472u-ddeb-rt10-m4cy

Logan, J., Hughes, T., \& Logan, B. (2016). Overworked? An observation of the relationship between student employment and academic performance. Journal of College Student Retention: Research, Theory, \& Practice, 18(3), 250-262. https://doi.org/10.1177/1521025115622777

Long, M.C. (2008). College quality and early adult outcomes. Economics of Education Review, 27(5), 588-602. https://doi.org/10.1016/j.econedurev.2007.04.004 
Mayers, R. F., Wilson, A. W. \& Potwarka, L. R. (2017). Moderating effects of campus recreation participation in the relationship between grade point average and first-year student engagement: An exploratory study. Recreational Sports Journal, 41(2), 101. https://doi.org/10.1123/rsj.2016-0021

Mayhew, M. J., Pascarella, E. T., Bowman, N. A., Rockenbach, A. N., Seifert, T. A., Terenzini, P. T., \& Wolniak, G. C. (2016). How college affects students: 21st century evidence that higher education works (Vol. 3). John Wiley \& Sons.

McElveen, M., \& Ibele, K. (2019). Retention and academic success of first-year student-athletes and intramural sports participants. Recreational Sports Journal, 43(1), 5-11. https://doi.org/10.1177/1558866119840466

McFadden, C. W., \& Stenta, D. A. (2015). Connecting collegiate recreation and athletics to leadership. New Directions for Student Leadership, 2015(147), 5-18. https://doi.org/10.1002/yd.20139

McFarland, J., Hussar, B., Zhang, J., Wang, X., Wang, K., Hein, S., Diliberti, M., Forrest Cataldi, E., Bullock Mann, F., and Barmer, A. (2019). The condition of education 2019 (pp. 196-201). (NCES 2019-144). National Center for Education Statistics. https://eric.ed.gov/?id=ED594978

Michael, J. M., Morris-Dueer, V., \& Reichert, M. S. (2017). Differential effects of participation in an outdoor orientation program for incoming students. Journal of Outdoor Recreation, Education, and Leadership, 9(1), 42-55. https://doi.org/10.18666/jorel-2017-v9-i1-7483

Miller, J. J. (2011). Impact of a university recreation center on social belonging and student retention. Recreational Sports Journal, 35(2), 117-129. https://doi.org/10.1123/rsj.35.2.117 
National Student Clearinghouse (NSC) Research Center. (2019). Persistence \& retention - 2019. National Student Clearinghouse. https://nscresearchcenter.org/snapshotreport35-firstyear-persistence-and-retention/

National Survey of Student Engagement. (2019). Engagement insights: Survey findings on the quality of undergraduate education - annual results 2019. Bloomington, IN: Indiana University Center for Postsecondary Research.

Radunzel, J. (2018). They may be first but will they last? Retention and transfer behavior of firstgeneration students. Working paper 2018-5. ACT. Retrieved from http://www.act.org/content/dam/act/unsecured/documents/R1708-retention-firstgen2018-04.pdf

Renaud, J., Britton, S., Wang, D., \& Ogihara, M. (2015). Mining library and university data to understand library use patterns. The Electronic Library, 33(3), 355-372. https://doi.org/10.1108/el-07-2013-0136

Rimmer, J. H., Padalabalanarayanan, S., Malone, L. A., \& Mehta, T. (2017). Fitness facilities still lack accessibility for people with disabilities. Disability and Health Journal, 10(4), 214-221. https://doi.org/10.1016/j.dhjo.2016.12.011

Robbins, S. B., Lauver, K., Le, H., Davis, D., Langley, R., \& Carlstrom, A. (2004). Do psychosocial and study skill factors predict college outcomes? A metaanalysis. Psychological Bulletin, 130(2), 261. https://doi.org/10.1037/00332909.130.2.261

Roddy, L. A., Pohle-Krauza R .J., \& Geltz, B. (2017). Recreation center utilization affects academic outcomes. Recreational Sports Journal, 41(1), 67-75. https://doi.org/10.1123/rsj.2016-0041 
Ryan, J. F. (2004). The relationship between institutional expenditures and degree attainment at baccalaureate colleges. Research in Higher Education, 45(2), 97-114. https://doi.org/10.1023/b:rihe.0000015691.02545.61

Seidman, A. (Ed.). (2012). College student retention: Formula for student success. Retrieved from https://ebookcentral.proquest.com

Shapiro, D., Dundar, A., Yuan, X., Harrell, A. T., Wild, J. C., \& Ziskin, M. B. (2014). Some college, no degree: A national view of students with some college enrollment, but no completion (Report No. 7). National Student Clearinghouse.

https://eric.ed.gov/?id=ED556472

Smith, J. A., \& Todd, P. E. (2005). Does matching overcome LaLonde's critique of nonexperimental estimators? Journal of Econometrics, 125, 305-353. https://doi.org/10.1016/j.jeconom.2004.04.011

Soria, K. M., \& Stebleton, M. J. (2012). First-generation students' academic engagement and retention. Teaching in Higher Education, 17(6), 673-685. https://doi.org/10.1080/13562517.2012.666735

Strayhorn, T. L. (2008). How college students' engagement affects personal and social learning outcomes. Journal of College and Character, 10(2). https://doi.org/10.2202/19401639.1071

Swail, W. S. (2004). The art of student retention: A handbook for practioners and administrators. Educational Policy Institute. https://eric.ed.gov/?id=ED485498

Tinto, V. (1975). Dropout from higher education: a theoretical synthesis of recent research. Review of Educational Research, 45(1), 89-125. https://doi.org/10.2307/1170024 
Tinto, V. (1993). Leaving college: Rethinking the causes and cures of student attrition (2nd ed.). University of Chicago Press. https://eric.ed.gov/?id=ED283416

Tinto, V. (2006). Research and practice of student retention: What next? Journal of College Student Retention: Research, Theory \& Practice, 8(1), 1-19. https://doi.org/10.2190/c0c4-eft9-eg7w-pwp4

Vasold, K. L., Deere, S. J., \& Pivarnik, J. M. (2019). Club and intramural sports participation and college student academic success. Recreational Sports Journal, 43(1), 55-66. https://doi.org/10.1177/1558866119840085

Vasold, K. L., Kosowski, L. E., \& Pivarnik, J. M. (2019). Academic Success and 1 Year of Intramural Sports Participation by Freshmen Students. Journal of College Student Retention: Research, Theory \& Practice, 0 (0), 1-10. https://doi.org/10.1177/1521025119833000

Zizzi, S., Ayers, S. F., Watson, J. C., \& Keeler, L. (2004). Assessing the impact of new student campus recreation centers. NASPA Journal, 41(4), 588-630.

https://doi.org/10.2202/0027-6014.1390 